\title{
Dynamic Characteristics Analysis of High Pier Steel Pipe Lattice Support System in Typhoon Region
}

\author{
Shijie Wang ${ }^{1,2}$, Quansheng Sun ${ }^{1, *}$, Hongshuai Gao ${ }^{1}$, Hongxiang Xia ${ }^{1}$ \\ ${ }^{1}$ School of Civil Engineering, Northeast Forestry University, Harbin, China \\ ${ }^{2}$ School of Civil and Architectural Engineering, Heilongiiang Institute of Technology, Harbin, China \\ Email address: \\ twfxwsj@163.com (Shijie Wang), hrbsqs@126.com (Quansheng Sun), ghsphd $a$ 126.com (Hongshuai Gao), \\ tauruskd $a$ nefu.edu.cn (Hongxiang Xia) \\ ${ }^{*}$ Corresponding author
}

\section{To cite this article:}

Shijie Wang, Quansheng Sun, Hongshuai Gao, Hongxiang Xia. Dynamic Characteristics Analysis of High Pier Steel Pipe Lattice Support System in Typhoon Region. American Journal of Civil Engineering. Vol. 8, No. 2, 2020, pp. 30-36. doi: 10.11648/j.ajce.20200802.12

Received: March 30, 2020; Accepted: April 14, 2020; Published: April 23, 2020

\begin{abstract}
According to similar criteria, the on-site lattice support on-site in the typhoon area is $62 \mathrm{~m}$ high and scaled down at 1: 150 to produce an aeroelastic scaled model of the lattice support. Based on the specifications and the characteristics of the wind field in the area where the project is located, a type A landform is used for wind tunnel tests. Through the measured structural dynamic characteristics combined with the help of the finite element analysis software Ansys, the dynamic characteristics of the lattice support under typhoon wind field were studied. The test results showed that under wind load, the lattice support itself is dominated by second-order low-frequency vibrations. The top end of the bracket is excited with a lower first-order frequency. The difference between the first-order and second-order natural frequencies is small. The support is about $\mathrm{H} / 3$ height or more, which is greatly affected by wind load and speed, and is less affected below $30 \mathrm{~m}$; at each wind direction angle, the acceleration response of each measurement point of the support generally increases non-linearly with the increase of wind speed. The response of the measuring point shows a quadratic curve relationship with the wind speed. The acceleration of the measuring point gradually decreases from the top to the bottom. At the same wind speed, the closer to the top, the larger the acceleration. The positive change is more than $\mathrm{H} / 2$, and the change period is unstable. Below $20 \mathrm{~m}$, the positive and negative acceleration changes relatively uniformly, the closer to the bottom, the smaller the acceleration period; the maximum value of the wind vibration response at each measurement point occurs under the wind angle of $0^{\circ}$ and $90^{\circ}$, the wind resistance generated by the box girder cross section has little effect on the support; at a wind angle of $45^{\circ}$, the response value of the crosswind and windward wind vibration is similar, and the effect of the crosswind cannot be ignored.
\end{abstract}

Keywords: Steel Tubular Lattice Support System, Wind Load, Wind Tunnel Test, Wind Direction Angle, Root Mean Square Acceleration

\section{Introduction}

In recent years, with the rapid economic development of China's coastal areas, more and more bridges have been built in this high typhoon-prone environment. Typhoon's atmospheric vortex area has huge energy, which makes them extremely destructive. They are different from ordinary strong winds and hurricane. They have denser rotating and converging airflows, extreme wind speeds and turbulence intensity, rising and sinking airflows, and drastic changes in wind direction, etc [1-2], which can easily cause structural damage. Measurements have confirmed that the typhoon climate model has the following characteristics: In the near-earth boundary layer of 200-300m, the change of average wind speed with height generally satisfies the power exponential relationship, and the average wind profile index $\alpha$ ranges from 0.1 to Between 0.3 [3-5]; both the turbulence intensity and the energy of the pulsating wind speed spectrum significantly exceed the corresponding values in a normal state wind field, and the wind spectrum is more discrete [6-7]. The field measurement can reflect the wind vibration response of the lattice support under specific typhoons and site conditions, but requires high accuracy of the equipment. 
Therefore, the current aeroelastic wind tunnel test is the most effective method for analyzing the vibration response of the structure [8]. At this stage, the wind vibration characteristics of different types of transmission towers, ground conductors, and tower-line coupling systems under the action of normal winds have been studied [9-11]. However, studies on the typhoon wind field used in the lattice support of bridges, particularly the influence of high turbulence characteristics on wind vibration response, is still relatively lacking.

The Pingtan Strait Bridge is located in the middle of the Pingtan Strait, 7.85 kilometers from the mainland. It is close to the Pacific Ocean and suffers storms of varying degrees each year. The wind intensity can reach 14 levels. The highway part of the bridge is composed of 5 segments: $4 \times 40 \mathrm{~m}$ continuous beam $+4 \times 40 \mathrm{~m}$ continuous beam $+6 \times 40 \mathrm{~m}$ continuous beam $+5 \times 40 \mathrm{~m}$ continuous beam $+4 \times 32 \mathrm{~m}$ continuous beam, a total of 23 spans. Due to the height of the bridge, the cast-in-situ support of the main beam adopts the "steel pipe column + Beley beam" structure system. For the special structure form of lattice tower, such as multi-point pressure measurement for high-rise buildings and large roof structures Wind tunnel test methods that are very effective for wind load testing are not applicable. Therefore, determining the wind load of a lattice tower by measuring the force of a high-frequency base balance has become the main wind tunnel test method that can be used at present [12].

\section{Experimental Program}

\subsection{Scaled Model and Wind Field Simulation}

In order to ensure the safety of construction, we selected the highest support $62.022 \mathrm{~m}$, that is, the lattice support structure between the pier numbers D10-D11 as the research object. The columns of the support adopt $\Phi 1200 \times 14 \mathrm{~mm}$ steel pipe, 4 rows in longitudinal direction and 2 rows in transverse direction. Lateral bracings of the support adopt $\Phi 720 \times 14 \mathrm{~mm}$ steel pipe, and the diagonal bracings adopt $\Phi 400 \times 8 \mathrm{~mm}$ steel pipe. The steel pipe pile column foundation is a bored pile foundation with a diameter of $1500 \mathrm{~mm}$. Double-height H700 $\times 300$ steel is placed on the top of the pile as the beam. The longitudinal beam adopts a single-layer Beret beam, and the layout principle is that the spacing between the bottom of the web is $450 \mathrm{~mm}$, and the spacing between the bottom, top, and bottom of the flange is $900 \mathrm{~mm}$. The overall arrangement of the support structure is shown in Figures 1 2.

\subsection{Scaled Model}

Considering the actual building and surrounding conditions, combined with the actual situation of the wind tunnel laboratory, the model geometric reduction ratio is determined to be 1: 150 . Based on the similarity theory, the aeroelastic model design not only meets the similarity to the prototype geometry, stiffness and mass distribution, but also need to ensure the consistency of multiple dimensionless parameters. Considering the limitations of the actual test conditions and the specific conditions of the support, we strictly ensure that the inertia parameters, elastic parameters and Strouhal numbers are similar, but be lenient on the simulation of the similarity of gravity parameters and viscosity parameters, as they have insignificant effect on the test results [13-15]. The similarity coefficient of the aeroelastic model is shown in Table 1.

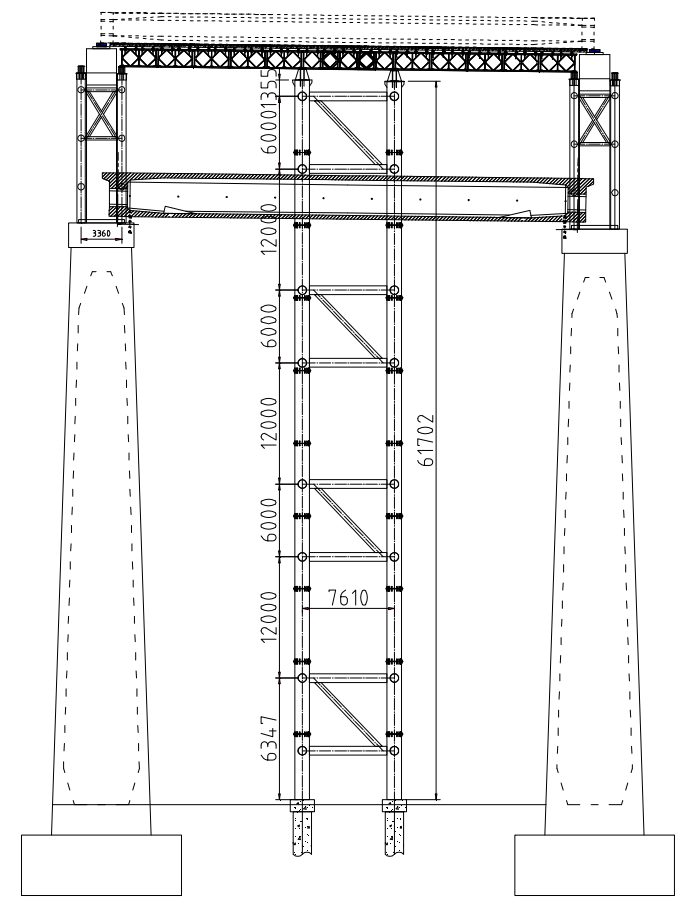

Figure 1. D10 D11 support longitudinal layout (mm).

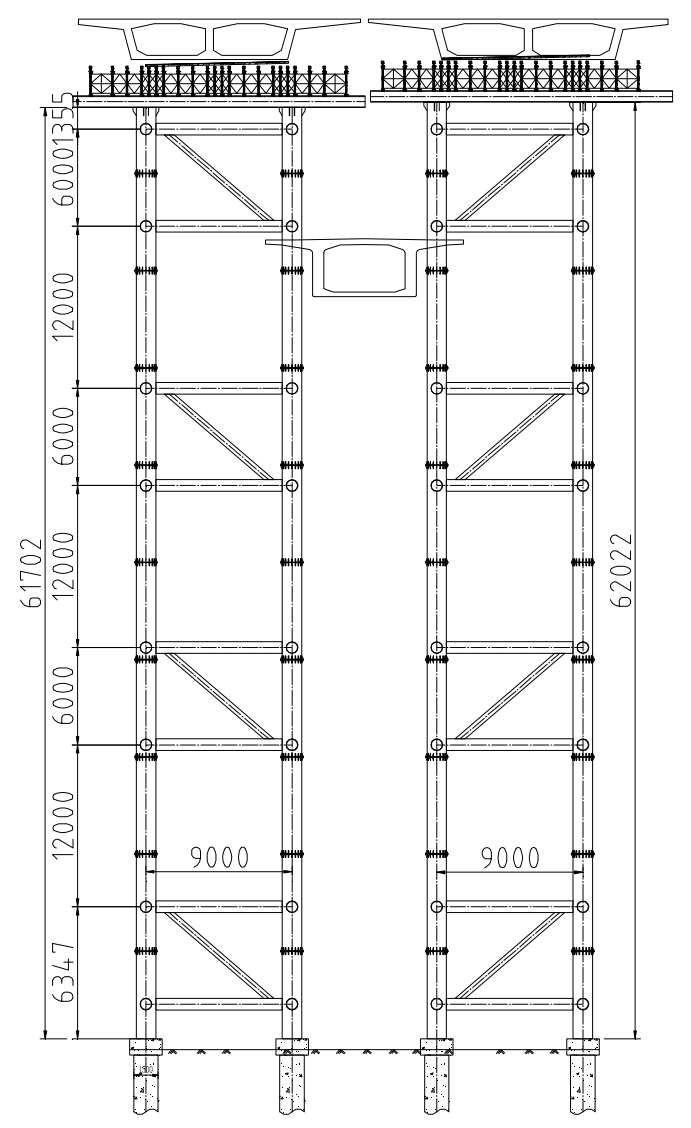

Figure 2. D10-D11 support transverse layout (mm). 
Table 1. Similar parameters of the aeroelastic model of the support.

\begin{tabular}{ll}
\hline Similarity coefficient & Value \\
\hline Size similarity coefficient $C_{\mathrm{L}}$ & $1 / 150$ \\
Density similarity coefficient $C_{P S}$ & 1.789 \\
Mass similarity coefficient $C_{m}$ & $1 / 3375000$ \\
Tensile stiffness similarity coefficient $C_{\mathrm{EA}}$ & $6 \mathrm{E}-5$ \\
Frequency similarity coefficient $\mathrm{C}_{\mathrm{f}}$ & 10.688 \\
Acceleration similarity coefficient $\mathrm{C}_{\mathrm{a}}$ & 0.761 \\
Wind speed similarity coefficient $\mathrm{C}_{\mathrm{v}}$ & 0.071 \\
\hline
\end{tabular}

\section{.3. Wind Field Simulation}

The reference wind speed of the test flow field was measured and monitored with a TFI Cobra three-dimensional pulsating wind speed measuring instrument. Atmospheric boundary layer simulated wind field was adjusted and verified using a system consisting of a cobra three-dimensional pulsating wind speed measuring instrument, an A / D converter, and a computer with specified software. The test data acquisition system consists of a six-component high-frequency force-measuring balance, an $\alpha$ angle attack angle change mechanism, an A / D converter, and a computer for data acquisition and processing. The signal sampling frequency is $1000 \mathrm{~Hz}$, the sampling time is $60 \mathrm{~s}$, and the total length of the sampling at each measurement point is 60,000 data. During the test, 60,000 wind pressure time domain signals were recorded for each and every measurement points and wind direction angles.

Based on the built environment within a few kilometres of the Pingtan Strait Bridge and with reference to the Chinese Code for Building Structure Loads (GB50009-2012), which will be referred to as the design code hereafter, the atmospheric boundary layer flow field simulation of this test was determined to be a type A geomorphic wind field. The simulation set-up is shown in Figure 3 below. The wind tunnel is set with 3 spikes, the spacing is $10 \mathrm{~cm}, 16.5 \mathrm{~cm}, 16.5 \mathrm{~cm}$, and $10 \mathrm{~cm} .8$ rough elements are placed, and the spacing is $3 \mathrm{~cm}, 3 \mathrm{~cm}, 4 \mathrm{~cm}, 4 \mathrm{~cm}$, $4 \mathrm{~cm}, 3.5 \mathrm{~cm}, 4 \mathrm{~cm}, 4 \mathrm{~cm}, 3 \mathrm{~cm}$, to simulate the ideal type A landform wind field [16 18]. The simulation results of mean wind speed profile and turbulence are shown in Figure 4 and Figure 5. It can be seen that the incoming wind field simulated by the wind tunnel is in good agreement with the design code. With respect to Wind-resistant Design Specification for Highway Bridges (JTG/T 3360-01-2018), the 10-year recurrence period in the Pingtan area is $\mathrm{Vs} 10=35.0 \mathrm{~m} / \mathrm{s}$, the gradient wind speed is "V" _"d" "=" "V" _"s10" (Z"10")^" $\alpha "$. In summary, the wind speed at the construction site is measured using the design reference wind speed $\mathrm{V}=44 \mathrm{~m} / \mathrm{s}$.

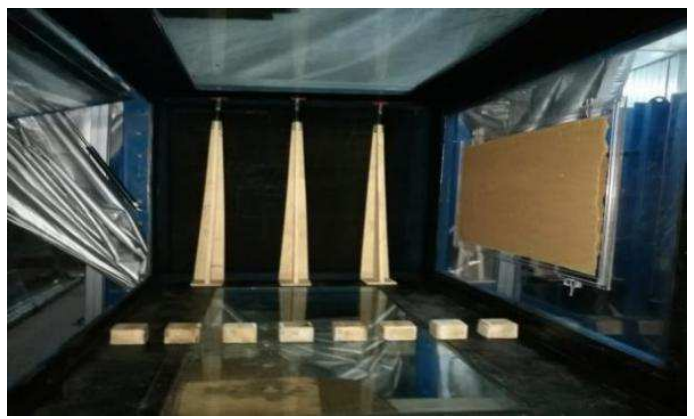

Figure 3. Type A landform simulated in a wind tunnel.

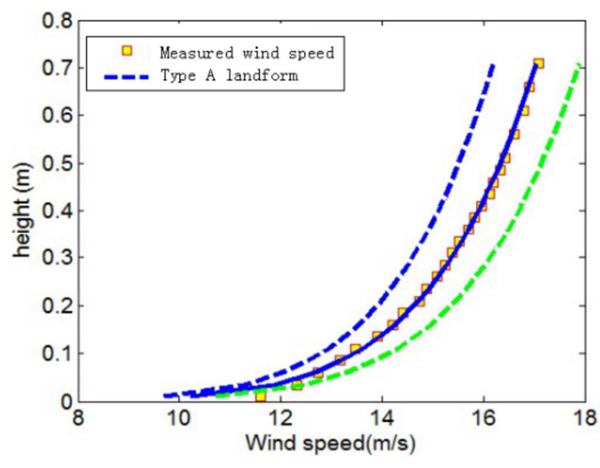

Figure 4. Mean wind profile in the wind tunnel

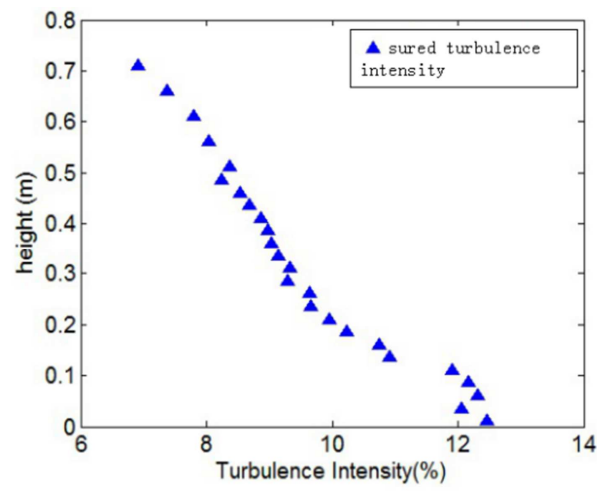

Figure 5. Measured turbulence in the wind tunnel.

\subsection{Test conditions}

The support arrangement at each location is shown in Figure 6 . The wind blows vertically to the east facade of the scaled model, and the wind direction angle increases counter clockwise. The test wind direction angle interval is $15^{\circ}$, and the wind direction angle is defined as shown in Figure 7.

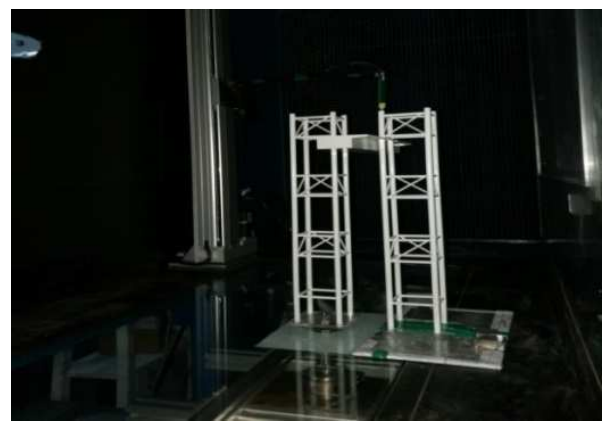

Figure 6. Scaled model and test condition of the support.

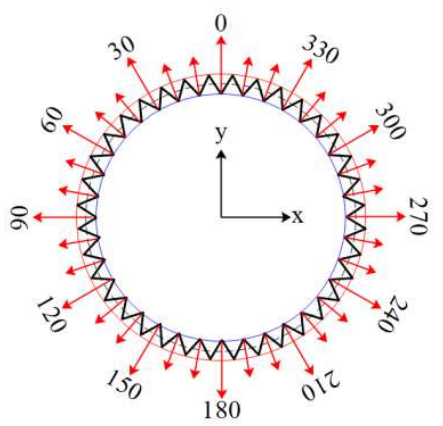

Figure 7. Schematic diagram of wind direction angles. 


\section{Dynamic Performance Analysis of Lattice Support}

\subsection{Calibration of Dynamic Characteristics}

Six measurement point layers are selected along the model height direction, and the heights are about $10 \mathrm{~m}, 20 \mathrm{~m}, 30 \mathrm{~m}$, $40 \mathrm{~m}, 50 \mathrm{~m}$, and $60 \mathrm{~m}$ from the ground; two acceleration sensors in the $\mathrm{X}$ direction and $\mathrm{Y}$ direction are arranged corresponding to each layer. According to the dynamic analysis of the actual support structure, the first three orders of natural vibration modes are first-order translational bending in the $\mathrm{Y}$ direction, first-order translational bending in the $\mathrm{X}$ direction, and first-order torsion, respectively. In addition, as shown in Table
2 that the first two-orders of calculated bending frequencies of the support are relatively close. In order to verify the consistency between the dynamic characteristics of the scaled model and the support on-site, the dynamic characteristics calibration test of the aero elastic model was carried out by using the force hammer excitation method before the vibration measurement test. The first-order torsional frequency was obtained from the response difference measurement point located on the top. Table 2 shows the calibration results of the dynamic characteristics. The measured frequency of the model is very close to the calculated frequency of the on-site support, which indicates that the model is reasonable and meets the similar conditions of dynamic characteristics.

Table 2. Natural frequency.

\begin{tabular}{llll}
\hline Mode & Scaled Model Calculation Frequency/Hz & Support Calculation Frequency / Hz & Scaled Model Measured Frequency / Hz \\
\hline $1^{\text {st }}$ order Y bending & 8.2707 & 0.774 & 8.16 \\
$1^{\text {st }}$ order X bending & 8.7988 & 0.804 & 8.63 \\
$1^{\text {st }}$ order torsion & 16.585 & 1.340 & 16.73 \\
\hline
\end{tabular}

\subsection{Analysis of Acceleration Response Spectrum in Typhoon Wind Field}

Figure 8 shows the acceleration power spectrum curve at $0^{\circ}$ wind direction angle with reference point wind speed at $44 \mathrm{~m} / \mathrm{s}$ of the measurement point $1-1,1-2$ and $6-1$, which located at the top of the support along $\mathrm{Y}$ direction (longitudinal), $\mathrm{X}$ direction (transverse), and $\mathrm{Y}$ direction $10 \mathrm{~m}$ above the bottom of the support, respectively. As shown in Figure 8 (a) that the acceleration power spectrum of the measurement point 1-1 has a single peak, and the main frequency corresponds to the first-order bending vibration in the $\mathrm{Y}$ direction of the top of the bracket. The main frequency of measurement points 1-2 and 6-1 in Figure 8 (b) and (c) agrees well with the structure's second-order natural frequency. To summarize, under wind load, the acceleration response spectrum characteristics of the support itself is still dominated by second-order low-frequency vibration. The top end of the bracket is excited with a lower first-order frequency. Y-direction bending vibration occurs before $\mathrm{X}$-direction bending vibration.

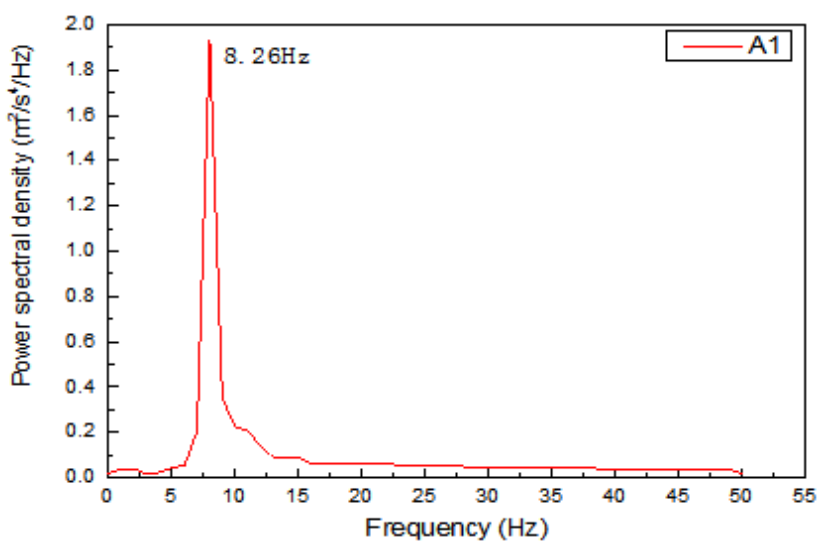

(a) A1, 60m above the ground.

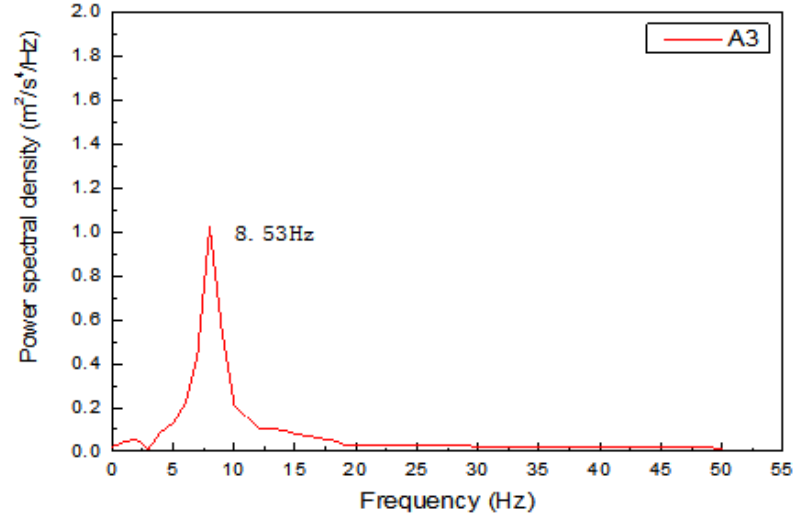

(b) A3, 30m above the ground.

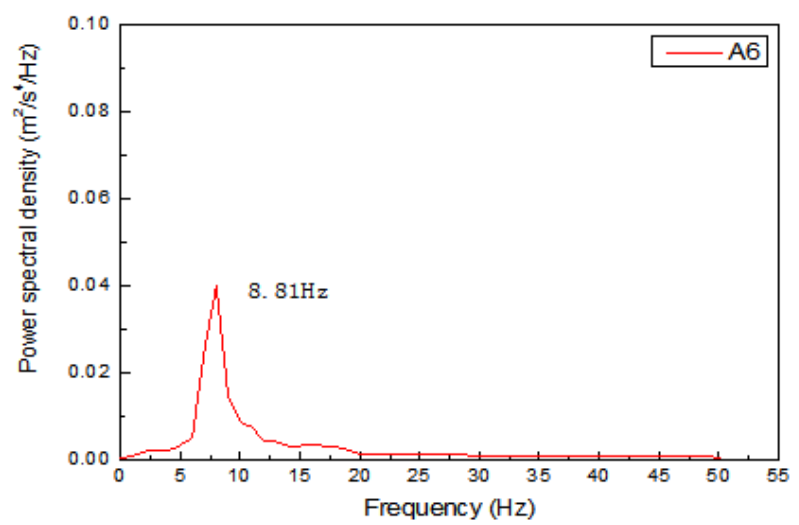

(c) A6, 10m above the ground.

Figure 8. Acceleration power spectrum of typhoon wind field at $0^{\circ}$ wind direction angle with reference point wind speed at $44 \mathrm{~m} / \mathrm{s}$ at each measuring point.

\subsection{Analysis of Acceleration Response in Typhoon Wind Field}

According to the acceleration similarity coefficient, the 
acceleration response collected in the model test can be converted to the prototype, and the relationship between the root mean square (RMS) response of each measurement point and the wind speed at the corresponding height of the prototype can be obtained. Measuring under the typical wind direction angles of $0^{\circ}, 45^{\circ}$, and $90^{\circ}$ for $10 \mathrm{~s}$, and the loading step is $0.1 \mathrm{~s}$. The velocity and acceleration changes along the longitudinal direction at varying support height layers are shown in Figures 9 and 10, respectively. The RMS time-history diagram of acceleration along X, Y-direction of each layer under wind direction angles of $0^{\circ}, 45^{\circ}$, and $90^{\circ}$ are shown in Figure 11.

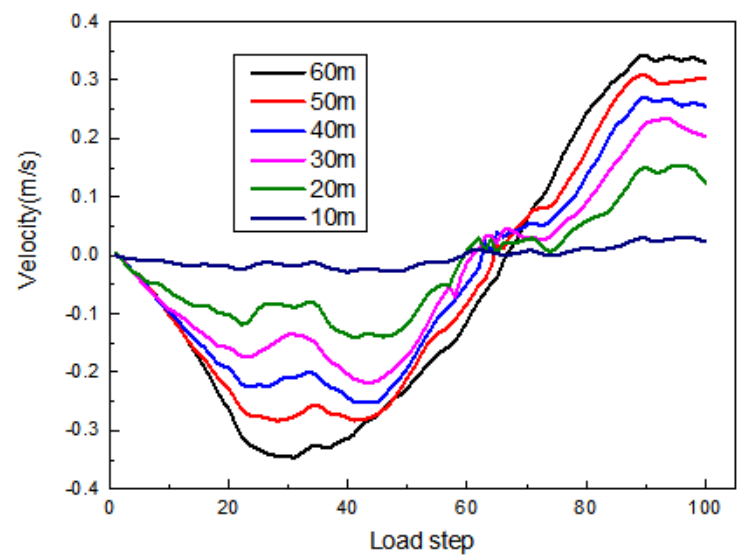

Figure 9. Velocity at varying heights under $0^{\circ}$ wind direction angle.

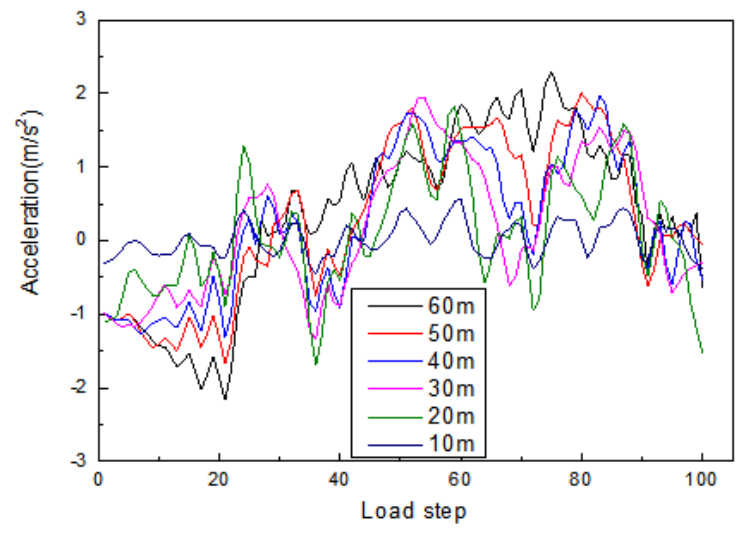

Figure 10. Acceleration at varying heights under $0^{\circ}$ wind direction angle.

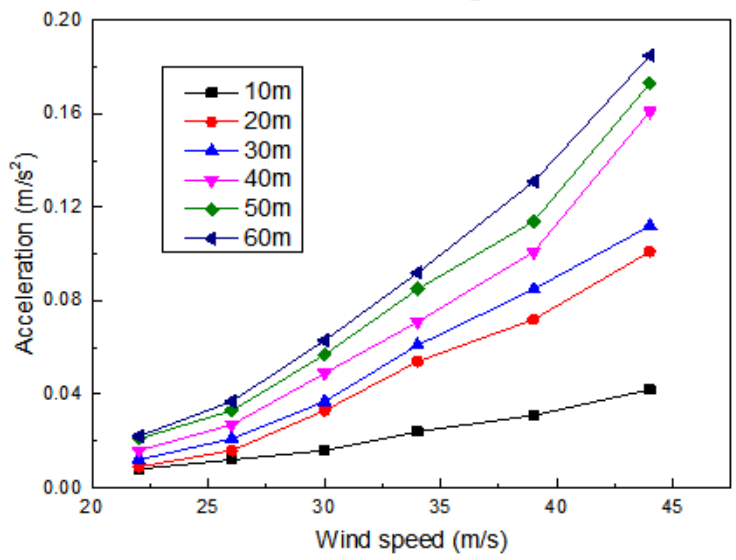

(a) $0^{\circ}$ wind direction angle, $\mathrm{X}$-directio.

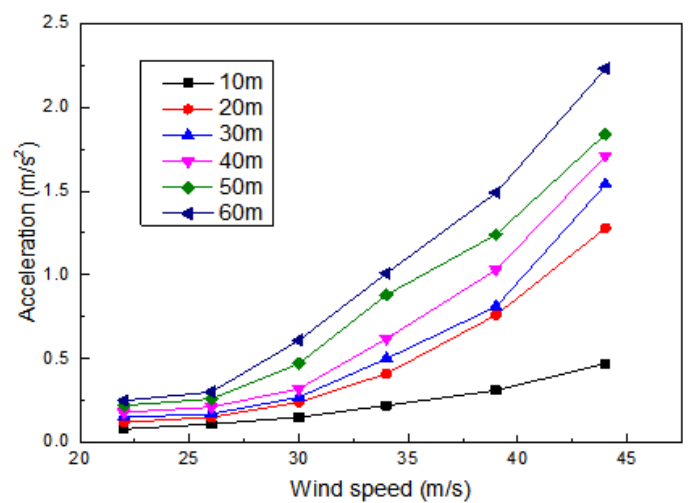

(b) $0^{\circ}$ wind direction angle, Y-direction.

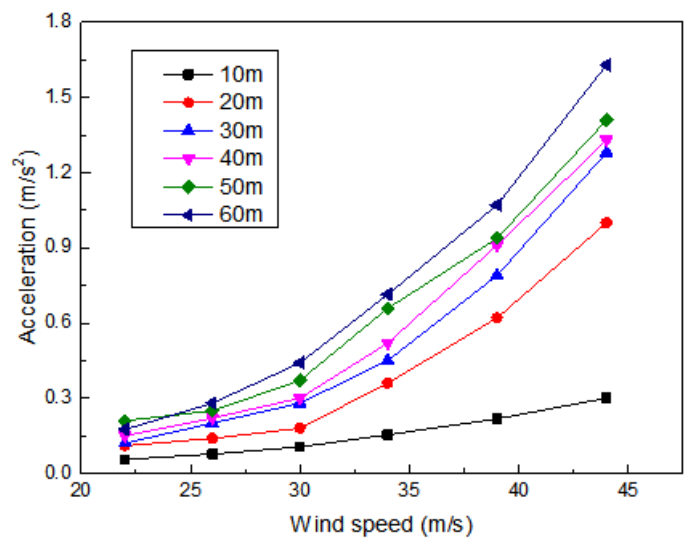

(c) $45^{\circ}$ wind direction angle, $\mathrm{X}$-directio.

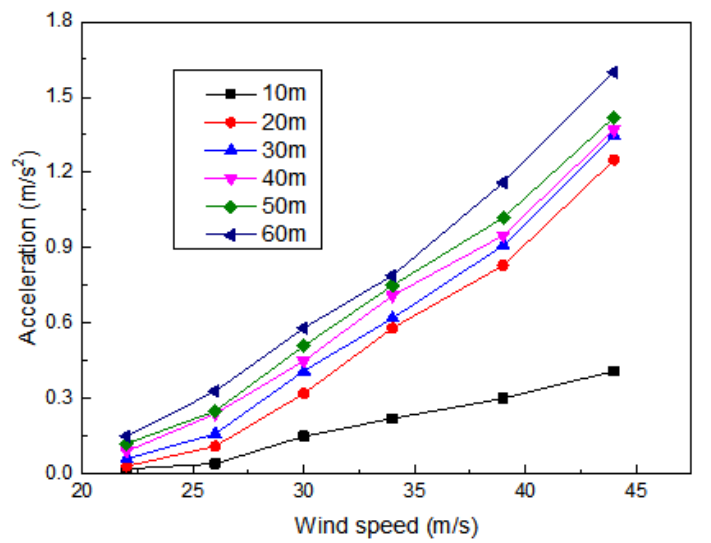

(d) $0^{\circ}$ wind direction angle, Y-direction.

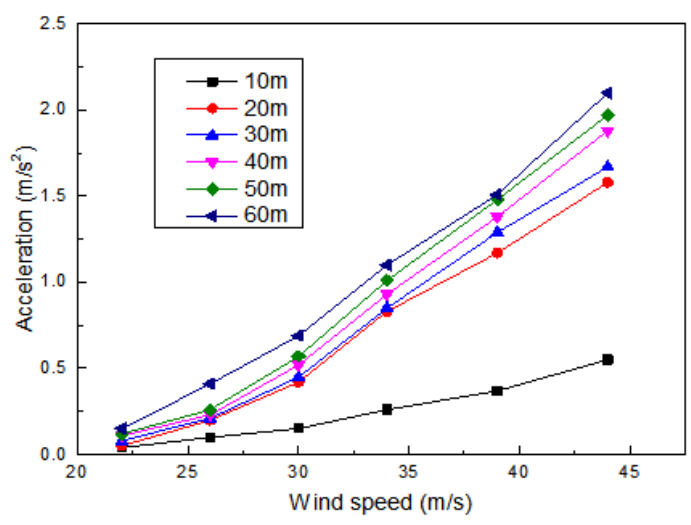

(e) $90^{\circ}$ wind direction angle, $\mathrm{X}$-direction. 


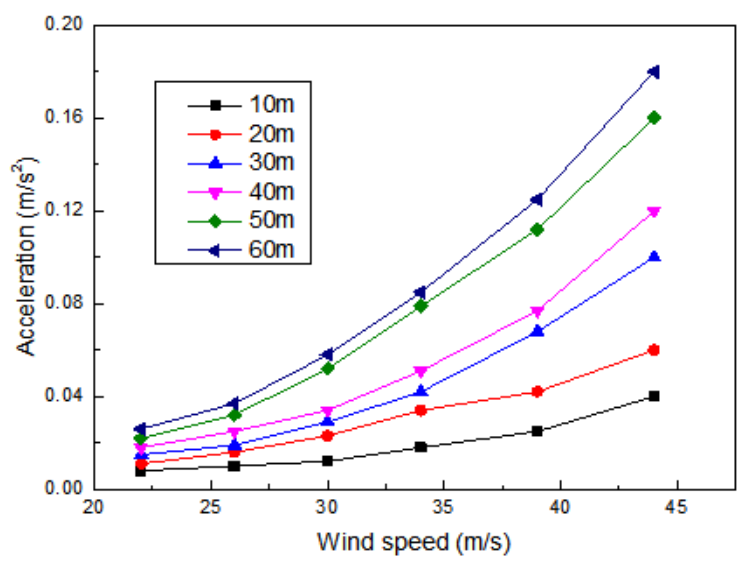

(f) $90^{\circ}$ wind direction angle, Y-direction.

Figure 11. RMS time-history diagram of velocity at each support layer under $0^{\circ}, 45^{\circ}, 90^{\circ}$ wind direction angle along either $X$ or Y-direction.

Analysis of Figures 9 to 11 leads to the following main conclusions:

1. Each part of the support velocity changes with time is close to a sinusoidal change. That is, the change swings back and forth with time around the initial point. The positive and negative maximum velocity occurs at steps 47 and 97 for the $10 \mathrm{~m}$ layer, at steps 46 and 90 for the $20 \mathrm{~m}$ layer, at steps 46 and 93 for the $30 \mathrm{~m}$ layer, at steps 42 and 90 for the $40 \mathrm{~m}$ layer, at steps 28 and 89 for the $50 \mathrm{~m}$ layer, at steps 31 and 89 for the $60 \mathrm{~m}$ layer. The difference in step distances is 61 47, maximum difference in steps occurs at layers $60 \mathrm{~m}, 50 \mathrm{~m}$, and $40 \mathrm{~m}$. The other three nodes difference is smaller, between 58-61, between 47 51. It can be seen that above $1 / 3$ height of the support, that is, more than $40 \mathrm{~m}$ is affected by the wind load, the duration is longer, and the displacement is larger. When it is less than $30 \mathrm{~m}$, the impact is smaller, and the closer it is to the top, the greater the speed will be.

2. Under each wind direction angle, the acceleration response of each measuring point of the support generally increases nonlinearly with the increase of wind speed, and the response of most of the measuring points presents a quadratic curve relationship with wind speed, and the acceleration of measuring point response gradually decreases from the top to the bottom.

3. The maximum acceleration response appears on the top of the support, $44 \mathrm{~m} / \mathrm{s}$ wind speed at steps 21 and 75 . The maximum RMS under wind load are $-2.16 \mathrm{~m} / \mathrm{s}^{2}$ and 2.16 $\mathrm{m} / \mathrm{s}^{2}$ at steps 21 and 81 , respectively. Maximum of $50 \mathrm{~m}$ measuring points occurs at step 21 and 81 , the maximum RMS are $-1.67 \mathrm{~m} / \mathrm{s}^{2}$ and $1.90 \mathrm{~m} / \mathrm{s}^{2}$, respectively. Maximum of $40 \mathrm{~m}$ measuring point occurs at step 7 and 83 , the maximum RMS are $-1.26 \mathrm{~m} / \mathrm{s}^{2}$ and $1.98 \mathrm{~m} / \mathrm{s}^{2}$, respectively. Maximum of $30 \mathrm{~m}$ measuring point occurs at step 36 and 54, maximum RMS are $-1.33 \mathrm{~m} / \mathrm{s}^{2}$ and $1.95 \mathrm{~m} / \mathrm{s}^{2}$, respectively. The measuring point of $20 \mathrm{~m}$ is at the step distance 36 and 59, and the maximum RMS are $-1.69 \mathrm{~m} / \mathrm{s}^{2}$ and $1.82 \mathrm{~m} / \mathrm{s}^{2}$, respectively. Maximum of $10 \mathrm{~m}$ measuring point occurs at step 36 and 60, the maximum
RMS are $-0.45 \mathrm{~m} / \mathrm{s}^{2}$ and $0.57 \mathrm{~m} / \mathrm{s}^{2}$, respectively. Generally speaking, under the same wind speed, the closer to the top, the acceleration increases correspondingly. Above $30 \mathrm{~m}$ are positive changes mostly, and the change period is unstable. When it is below $20 \mathrm{~m}$, the positive and negative changes of the acceleration are relatively uniform, and the closer it is to the bottom, the smaller the acceleration period is.

4. At the wind direction angle of $0^{\circ}$, the RMS value of acceleration at the measuring points in the $\mathrm{X}$ and $\mathrm{Y}$ directions of the same layer of the support is drastically different. The wind vibration response at the measuring points in the $\mathrm{Y}$ direction (inbound wind) at each layer is much higher than that at the measuring points in the $\mathrm{X}$ direction, indicating that the downwind response is dominant, while the transverse wind response is auxiliary. Under the $45^{\circ}$ wind direction Angle, the RMS value of the acceleration at the measuring points in the $\mathrm{X}$ and $\mathrm{Y}$ directions are relatively close, and the downwind and transverse wind direction responses need to be considered. The RMS value of the acceleration at the measuring points in the $90^{\circ}$ wind direction angle along $\mathrm{X}$ and $\mathrm{Y}$ is similar to the wind direction Angle of $0^{\circ}$, which is still dominated by the response value of the incoming wind direction. It can be seen that the wind resistance generated by the box girder section has little influence on the support, the test results of the lattice support and the high-rise tower (transmission tower) are the same, and the lattice support needs to respond to the influence of the transverse wind direction.

\section{Conclusions}

The scaled model test of cast-in-place main girder lattice support in typhoon area was carried out, and the construction site lattice support was also tested. The static and dynamic characteristics of the lattice support were analyzed through finite element software, and the following conclusions were obtained:

1. Under wind load, the support itself is still dominated by the second-order low-frequency vibration, and the lower first-order frequency is excited at the top of the support. The bending vibration in the $\mathrm{Y}$ direction occurs before the bending vibration in $\mathrm{X}$ direction.

2. About $1 / 3$ above the height of the lattice support, that is, above $40 \mathrm{~m}$ is greatly affected by the wind load and that the displacement is larger, and is less affected when it is less than $30 \mathrm{~m}$. The closer it is to the top, the greater the speed will be.

3. Under the same wind speed, when it is close to the top, the acceleration increases correspondingly, and the positive changes above $30 \mathrm{~m}$ are most prominent, and the change period is unstable. When it is below $20 \mathrm{~m}$, the positive and negative changes of the acceleration are relatively uniform. The closer it is to the bottom, the smaller the acceleration period is.

4. Under each wind direction angle, the acceleration 
response of each measuring point of the support generally increases nonlinearly with the increase of wind speed, and the response of majority of the measuring points presents a quadratic curve relationship with wind speed. The acceleration of measuring point response gradually decreases from the top to the bottom of the support.

5. The maximum wind vibration response of each measuring point occurs at the wind direction angles of $0^{\circ}$ and $90^{\circ}$. Wind resistance generated by the box girder section has little influence on the support. At a $45^{\circ}$ wind direction angle, the transverse wind direction is close to the downwind vibration response value, so the effect of transverse wind cannot be ignored.

\section{Author Contributions}

Conceptualization, S. W.

\section{Funding}

This research was funded by Natural science foundation of China (51378153) and Harbin Talent Fund Project (Grant No. RC2017QN012019).

\section{Conflicts of Interest}

The authors declare that they have no competing interests.

\section{References}

[1] Li, L.; Kareem, A.; Xiao, Y.; Song, L.; Zhou, C. A comparative study of field measurements of the turbulence characteristics of typhoon and hurricane winds. J. Wind Eng. Ind. Aerodyn. 2015 $140,49-66$.

[2] Cao, S.; Tamura, Y.; Kikuchi, N.; Saito, M.; Nakayama, I.; Matsuzaki, Y. Wind characteristics of a strong typhoon. J. Wind Eng. Ind. Aerodyn. 2009, 97, 11-21.

[3] CHOI E C C. Characteristics of typhoons over the south China sea [J]. Journal of Industrial Aerodynamics, 1978, 3 (4): 353-365.

[4] CHOI E C C. Gradient height and velocity profile during typhoons [J]. Journal of Wind Engineering and industrial Aerodynamics, 1983, 13 (1-3): 31-41.

[5] Shao Demin, Duan Yihong, Zhang Wei. Observation and analysis of typhoon wind speed profile characteristics in Shanghai. The Eleventh National Structural Engineering-Wind Engineering Conference Proceedings [C]. Hainan Sanya, 2004: 87-91 (in Chinese).
[6] Fang Pingzhi, Zhao Bingke, Shao Demin, etc. Characteristics of atmospheric turbulence near the ground before and after "Sepat" typhoon. The Forteenth National Structural Engineering-Wind Engineering Conference Proceedings [C]. Beijing, 2009: 7-62 (in Chinese).

[7] SONG Lili, MAO Huiqin, HUANG Haohui, et ai. Analysis on boundary layer turbulent features of landfalling typhoon [J]. Acta Meteorological Sinica, 2005, 63 (6): 915-921 (in Chinese).

[8] LI Jie, YAN Qi, XIE Qiang, et al. Wind field measurements and wind-induced vibration responses of transmission tower during typhoon wipha [J]. Journal of Building Structures, 2009, 26 (2): 1-8 (in Chinese).

[9] LOU Wenjuan, SUN Binnan, TANG Jinchun. Wind tunnel test and numerical computation on wind-induced vibration for tall lattice tower [J]. Journal of Vibration Engineering, 1996, 19 (3): 318-322 (in Chinese).

[10] LIANG Shuguo, ZOU Lianghao, HAN Yinquan, etal. Study of wind tunnel tests of a full aero-elastic model of electrical transmission tower-line systems [J]. China Civil Engineering Journal, 2010, 43 (5): 70-78. (in Chinese).

[11] ZHAO Gguifeng, XIE Qiang, LIANG Shuguo, et al. Wind tunnel test on Wind-induced response of transmission tower and tower line coupling system $[\mathrm{J}]$. Journal of Building Structures, 2010, 32 (2): 69-77 (in Chinese).

[12] LIANG Shuguo, ZOU Lianghao, ZHAO Lin, GE Yaojun. Analytical Model of Dynamic Wind Loads on Lattice Towers. Journal of Tongji University (Natural Science) [J].2008, 36 (2): 166-171. (in Chinese).

[13] Chen, Junfan. Study on The Three-component Coefficients of Latticed Tower Constructed from Cylindrical Members under The Static Wind [D]. Chongqing University, 2016, 2-4. (in Chinese).

[14] Cheng $\mathrm{J}, \mathrm{Xu} \mathrm{H}$. Inner mass impact damper for attenuating structure vibration $[\mathrm{J}]$. International Journal of Solids and Structures, 2006, 43 (17): 5355-5369.

[15] Li K, Darby A P. An experimental investigation into the use of a buffered impact damper [J]. Journal of Sound and Vibration, 2006, 291 (3-5): 844-860.

[16] Tokoro S, Komatsu H, Nakasu M, et al. A study on wake-galloping employing full aeroelastic twin cable model [J] 2000, 88 (2-3): 247-261

[17] Chen W L, Li H, Hu H. An experimental study on a suction flow control method to reduce the unsteadiness of the wind loads acting on a circular cylinder [J]. Experiments in Fluids, 2014, 55 (4): 1707-70.

[18] Daniel Duda, Jindřich Bém, Vitalii Yanovych, Petr Pavlíček, Václav Uruba. Secondary flow of second kind in a short channel observed by PIV. European Journal of Mechanics / B Fluids, 2019: 444-453. 